\title{
Changes in the expression of FoxO1 and death ligand genes during follicular atresia in porcine ovary
}

\author{
F. Lin, Y.H. Fu, J. Han, M. Shen, C.W. Du, R. Li, X.S. Ma and H.L. Liu \\ Department of Animal Genetics, Breeding and Reproduction, \\ College of Animal Science and Technology, Nanjing Agricultural University, \\ Nanjing, Jiangsu, China \\ Corresponding author: H.L. Liu \\ E-mail: liuhonglin@263.net
}

Genet. Mol. Res. 13 (3): 6638-6645 (2014)

Received September 26, 2013

Accepted December 6, 2013

Published August 28, 2014

DOI http://dx.doi.org/10.4238/2014.August.28.8

\begin{abstract}
Follicular atresia, a key phenomenon in follicle development, eliminates most of the follicles in mammalian ovaries. To investigate the molecular mechanism of follicular atresia in porcine ovaries, we investigated the mRNA expression of three important cell death ligand-receptor systems and Fox O1 in follicles with a diameter of 3-5 mm. The phosphorylation and subcellular localization of Fox O1 during granulosa cell apoptosis was also determined. TRAIL and Fas L played an important role in follicular atresia at this stage. Fox $\mathrm{O} 1$ expression was upregulated during atresia, and was confined to the nucleus of granulosa cells; however, phosphorylated Fox O1 was localized to the cytoplasm. These results suggest Fox O1 involvement in the regulation of TRAIL and Fas L expression during follicular atresia in pigs.
\end{abstract}

Key words: Follicular atresia; Apoptosis; Fox O1 


\section{INTRODUCTION}

In mammalian ovaries, more than $99 \%$ of follicles disappear during follicular growth and development in a phenomenon known as 'follicular atresia'; thus, only a limited number of follicles develop to ovulation (Takagi et al., 2007). Many researchers have investigated the molecular mechanism underlying atresia. Factors such as reproductive hormones, growth hormones, cell adherence molecules, and apoptosis-related genes have been reported to be involved in atresia (Kaipia and Hsueh, 1997; Hussein, 2005; Matsuda-Minehata et al., 2006). However, follicular atresia is thought to be a complex physiological process, and follicles at different stages of development may undergo atresia as a result of different mechanisms (Alonso-Pozos et al., 2003). The exact mechanism by which follicular atresia is regulated remains unknown.

Granulosa cell apoptosis has been suggested to be the trigger for follicular atresia (Grotowski et al., 1997; Rolaki et al., 2005), and investigations of the mechanism of follicular atresia regulation in porcine ovaries have been conducted. Some death ligand-receptor systems have been reported to be involved in the regulation of granulosa cell apoptosis during follicular atresia in porcine ovaries (Manabe et al., 2004, 2008). TNF, TRAIL, and Fas $\mathrm{L}$, with their respective receptors, represent three important death ligand-receptor systems. Whether these work together or alone, and which plays the dominant role in the regulation of granulosa cell apoptosis during different phases of follicular atresia, remain to be elucidated.

Fox $\mathrm{O} 1$ is a transcription factor implicated in a number of physiological processes, including apoptosis, cell cycle progression, and signaling (Schmidt et al., 2002; Neufeld, 2003; Alikhani et al., 2005; McLoughlin et al., 2009). Three conserved residues (threonine 24, serine 256 , and serine 319 ) are closely correlated with the phosphorylation and dephosphorylation of Fox O1. The PI3K/Akt signaling pathway is crucial for the regulation of Fox O1 phosphorylation. Akt directly phosphorylates Fox O1, which then binds to 14-3-3 proteins, which facilitate the translocation of Fox O1 from the nucleus to the cytoplasm (Biggs et al., 1999; Arden and Biggs, 2002; Birkenkamp and Coffer, 2003; Carter and Brunet, 2007). This nuclear exclusion and translocation to the cytoplasm inhibits Fox O1-dependent transcription. Fox O1 also regulates the expression of pro-apoptotic genes such as Fas L, TRAIL, and Bim (Brunet et al., 1999; Modur et al., 2002; Gilley et al., 2003).

In this study, we selected 3-5-mm (in diameter) follicles to determine which death ligand-receptor system(s) plays the dominant role in atresia at this stage. We also investigated the phosphorylation and distribution of Fox $\mathrm{O} 1$ in granulosa cells during apoptosis.

\section{MATERIAL AND METHODS}

\section{Animals and follicle separation}

Porcine ovaries were obtained from mature sows at a local slaughterhouse and transferred to the laboratory as soon as possible in PBS at $37^{\circ} \mathrm{C}$. Next, individual pre-ovulatory antral follicles, 3-5 $\mathrm{mm}$ in diameter, were dissected from the ovaries under a surgical dissecting microscope (SZ40; Olympus, Tokyo, Japan) with small scissors and forceps. The follicles were placed in PBS in a plastic dish. 


\section{Morphological observation}

Each follicle was classified as healthy $(\mathrm{H})$, early atretic (EA), or progressively atretic (PA) according to previous studies. Briefly, the $\mathrm{H}$ follicles were round with a continuous membrane around the granulosa cells, a fixed and visible cumulus-oocyte complex (COC), and clear follicular fluid. The EA follicles could still have a visible COC but with gaps in the granulosa cell membrane, and turbid follicular fluid. The PA follicles lacked a COC or had a $\mathrm{COC}$ in the follicular fluid with a dark floccule.

\section{Real-time PCR}

Total RNA from each follicle was extracted using TRIzol reagent (Invitrogen Corporation, Carlsbad, CA, USA), and reverse-transcription reactions were performed with MLV according to the manufacturer protocol. Real-time PCR was performed using SYBR Premix Ex Taq in a reaction volume of $20 \mu \mathrm{L}$. Twenty follicles per group were used. The primer sequences are shown in Table 1.

\begin{tabular}{|c|c|c|c|c|}
\hline Gene & NCBI entry number & Primer sequence & Product (bp) & Annealing temperature $\left({ }^{\circ} \mathrm{C}\right)$ \\
\hline GAPDH & AF017079 & $\begin{array}{l}\text { F: GATGG TGAAG GTCGG AGTG } \\
\text { R: CGAAG TTGTC ATGGA TGACC }\end{array}$ & 500 & 58 \\
\hline TNF & X57321 & $\begin{array}{l}\text { F: ACG CTC TTC TGC CTA CTG C } \\
\text { R: TCC CTC GGC TTT GAC ATT }\end{array}$ & 162 & 58 \\
\hline TRAIL & AY639873 & $\begin{array}{l}\text { F: TAA TTG GCT AAA TGA TCT GC } \\
\text { R: GCC TTA ACC TAT TGG CTC T }\end{array}$ & 101 & 53 \\
\hline Fas L & AY033634 & $\begin{array}{l}\text { F: CTCAA GATCC ATCCC TCTGG } \\
\text { R: TCATC TTTCC CTCCA TCAGC }\end{array}$ & 227 & 58 \\
\hline Fox O1 & NM_214014 & $\begin{array}{l}\text { F: TTCGGTCATGCCAGCCTAC } \\
\text { R: TCGCTCAGCCTGACACCC }\end{array}$ & 470 & 60 \\
\hline
\end{tabular}

\section{Immunocytochemistry}

Granulosa cells were collected from follicles and subjected to immunofluorescence staining. Briefly, the cells were fixed, permeabilized, and blocked, followed by incubation with anti-Fox O1 antibodies (Epitomics) overnight. The cells were then rinsed and incubated with anti-rabbit IgG (Cy3-labeled). After counterstaining with DAPI, the cells were observed under a fluorescence microscope.

\section{RESULTS}

\section{Morphological features of follicular atresia}

The $\mathrm{H}$ follicles were red and round with abundant blood vessels: the membranes of the granulosa cells were continuous and tight. The EA follicles appeared pink with fewer blood vessels: the granulosa cells became apoptotic and fell into the follicular antrum, and the follicular fluid was slightly turbid. The PA follicles were white: the mass of granulosa cells were apoptotic and fell into the follicular cavity, the follicular fluid became very turbid, and floccules could be seen (Figure 1). 


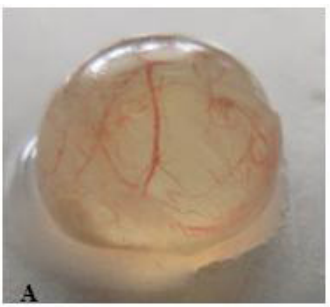

H

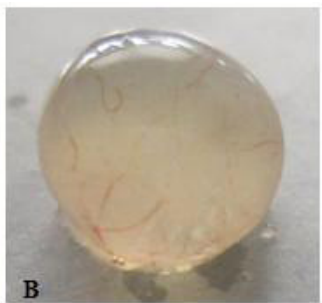

EA

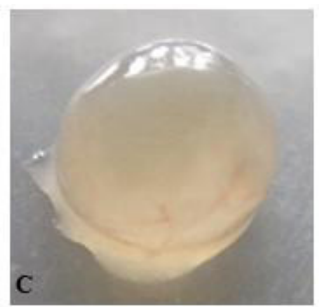

PA

Figure 1. Features of follicular atresia in pigs. $\mathrm{H}=$ healthy; $\mathrm{EA}=$ early atretic; $\mathrm{PA}=$ progressively atretic.

\section{Expression of cell death ligand genes during atresia}

TRAIL, Fas L, TNF, and Fas gene expression was quantified by real-time PCR in both $\mathrm{H}$ and atretic follicles (Figure 2). TRAIL, Fas L, and Fas gene expression was significantly increased during the early stage of follicular atresia.
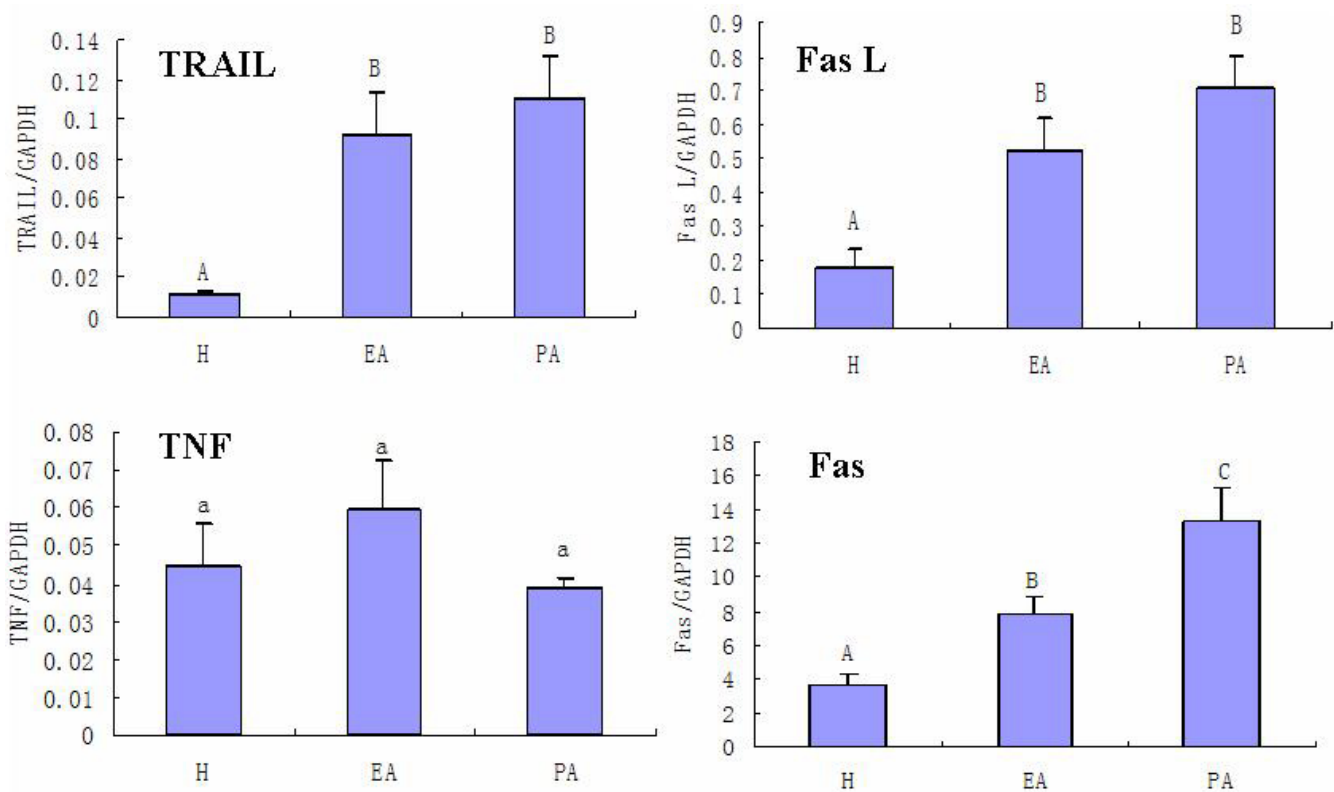

Figure 2. Gene expression during follicular atresia. Apoptotic pathway gene expression was detected by real-time PCR. Total RNA from 20 follicles per group was extracted. TRAIL, Fas L, and Fas expression was increased significantly during follicular atresia in porcine ovary. Different uppercase letters mean extremely significant difference $(\mathrm{P}<0.01)$. The same lowercase letters indicate the difference was not significant $(\mathrm{P}>0.05)$.

\section{Variation in gene expression in $\mathrm{H}$ 3- to 5-mm follicles}

Since the expression of TRAIL, Fas L, and Fas increased during porcine follicular atresia, we further analyzed their expression in $\mathrm{H}$ follicles. The expression of these genes in some $\mathrm{H}$ follicles reached or exceeded the mean in the early or late follicular atresia groups (Figure 3 ). 

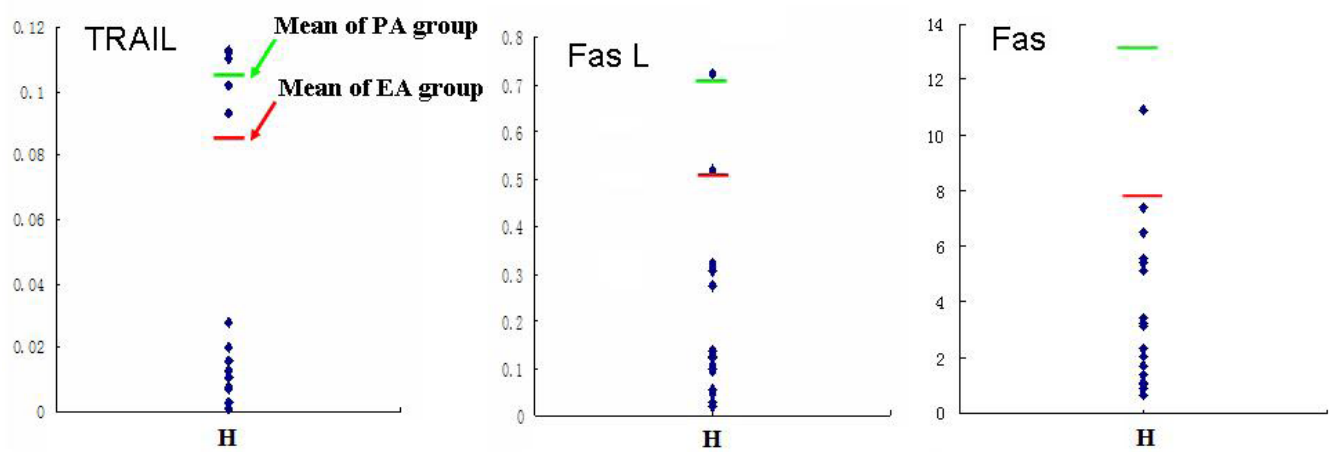

Figure 3. Gene expression variance in healthy $(\mathrm{H})$ follicles. TRAIL, Fas L, and Fas gene expression was quantified by real-time PCR. The expression in each $\mathrm{H}$ follicle was compared with that in early atretic (EA) and progressively atretic (PA) follicles. The mean values of the EA and PA follicles are indicated by red and green lines, respectively.

\section{Fox 01 expression during follicular atresia}

TRAIL, Fas L, and Fas expression is regulated by the transcription factor Fox O1; thus, the Fox O1 mRNA levels in H, EA, and PA follicles were quantified by real-time PCR. Fox $\mathrm{O} 1 \mathrm{mRNA}$ expression increased during follicular atresia $(\mathrm{P}<0.05$, Figure 4$)$.

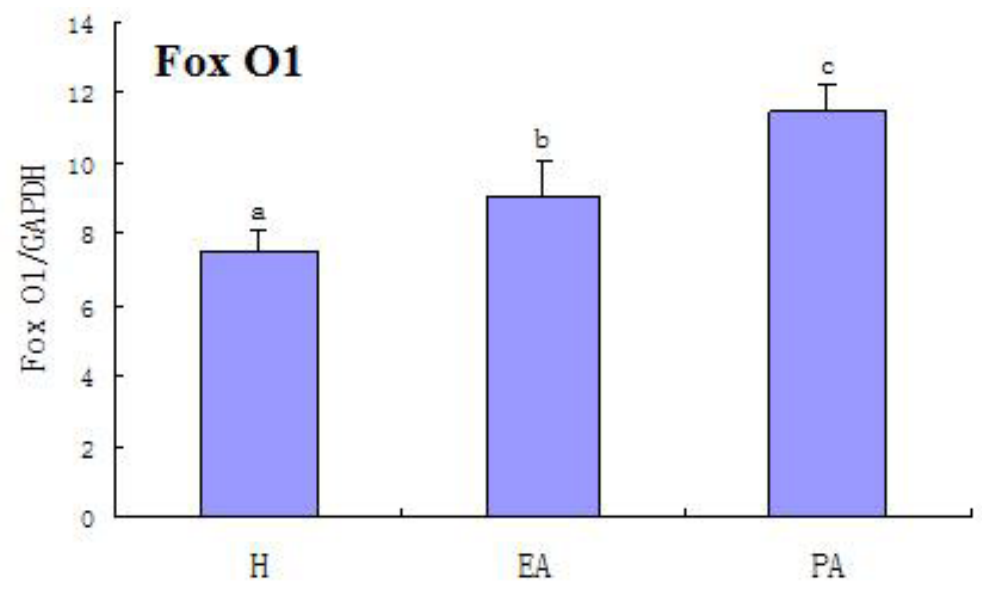

Figure 4. Fox $\mathrm{O} 1$ gene expression during follicular atresia. Fox $\mathrm{O} 1$ gene expression was detected by real-time PCR as mentioned above. For abbreviations, see legend to Figure 1.

\section{Location of Fox $\mathrm{O} 1$ in porcine granulosa cells}

Immunocytochemistry was performed to investigate the correlation between Fox O1 protein intracellular localization and its phosphorylation in pig granulosa cells. Unphosphorylated Fox $\mathrm{O} 1$ protein was located mainly in the nuclei of granulosa cells, and was translocated to the cytoplasm after phosphorylation (Figure 5). 


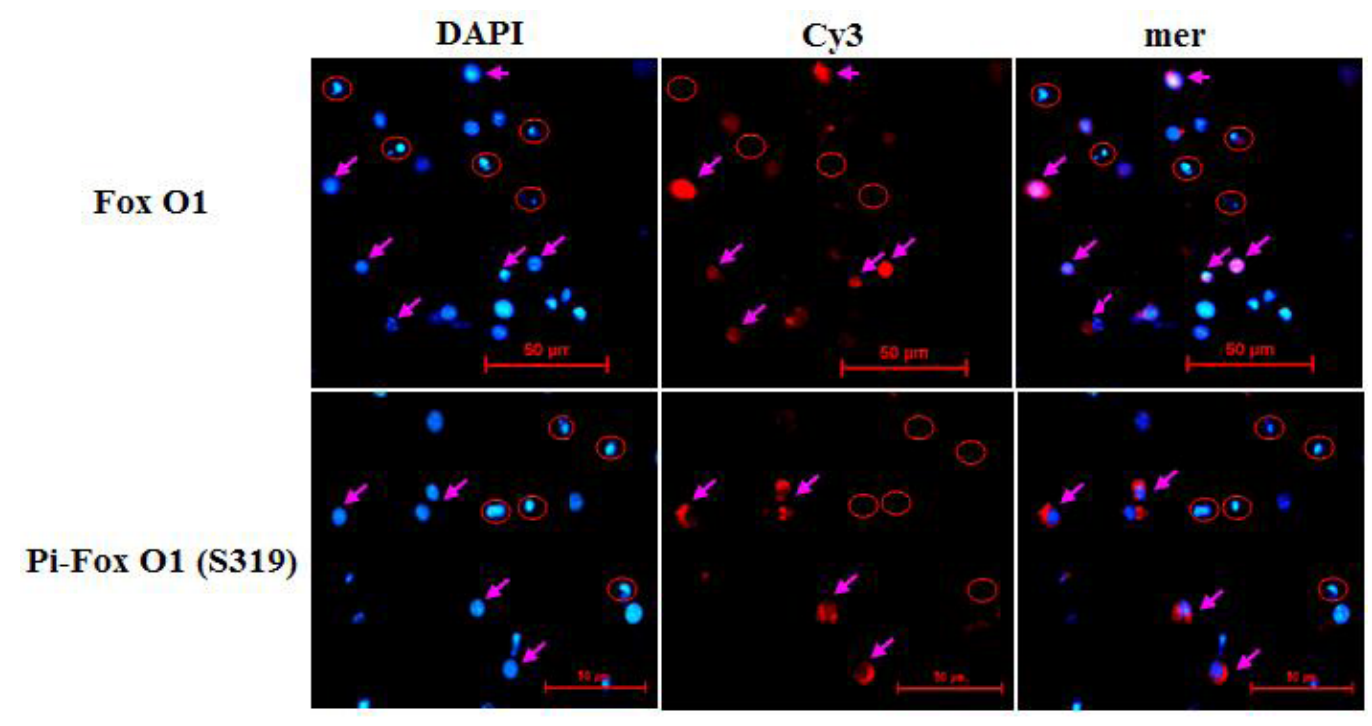

Figure 5. Intracellular location of Fox $\mathrm{O} 1$ in pig granulosa cells. Immunofluorescence cytochemistry was used to determine the subcellular localization of Fox O1. DAPI was used to stain the DNA. Fox O1 was expressed in the nuclei of some granulosa cells (top, arrows); however, it was not detected in apoptotic bodies (top, circled). Fox O1 phosphorylation occurs only in healthy granulosa cells, and phosphorylated Fox $\mathrm{O} 1$ is translocated to the cytoplasm (bottom, arrows). Fox $\mathrm{O} 1$ phosphorylation was not detected in apoptotic bodies (bottom, circled).

\section{DISCUSSION}

Most porcine ovarian follicles undergo atresia before reaching $6 \mathrm{~mm}$ in diameter (Manabe et al., 2004), so the mechanism of atresia within follicles 3-5 mm in diameter is representative. There are about five million primordial follicles in pigs ten days after birth, of which at most 1600 develop to ovulation during the breeding period (Manabe et al., 2004). The vast majority of follicles undergo atresia at various stages of development. Follicular atresia in pigs is regulated by many factors (Kimura et al., 1999; Wada et al., 2002; Matsuda-Minehata et al., 2005; Maeda et al., 2007; Cheng et al., 2005, 2008; Matsuda et al., 2008; Sugimoto et al., 2010). Manabe et al. (2004) summarized five apoptosis signaling pathways and emphasized the importance of three cell death ligand-receptor systems, TNF-TNFR, Fas L-Fas, and TRAIL-TRAILR. Different stages of follicular atresia may have different regulatory mechanisms (Alonso-Pozos et al., 2003), and which system plays the most important role in the middle atresia of follicles with a diameter of 3-5 mm is not known. Therefore, we investigated the expression of the three aforementioned death ligand genes during atresia. Our results suggest that the TRAIL and Fas L, but not TNF, pathways play an important role at this stage. TRAIL, Fas L, and Fas gene expression in EA follicles was significantly increased and remained high during late-stage atresia. Therefore, these two pathways play an important regulatory role not only in the initiation of follicular atresia, but also in its further promotion.

Analysis of variance of gene expression in the healthy group indicated that Fas and TRAIL expression in some $\mathrm{H}$ follicles met or exceeded that in the EA or PA follicles. This implied that abnormal gene expression may be an early event in follicle atresia and that gene 
expression abnormalities may precede the appearance of features of follicular atresia, because healthy follicles were confirmed by morphology in this research. Moreover, this suggests that follicles with increased expression of apoptosis pathway genes may undergo atresia in the future.

The transcription factor Fox O1 remains in the nucleus and stimulates the expression of genes such as Fas L, TRAIL, and Bim, so as to inhibit cell proliferation and promote apoptosis (Brunet et al., 1999; Modur et al., 2002; Carter and Brunet, 2007). Our data showed that the atresia of porcine follicles 3-5 mm in diameter is regulated mainly by the Fas $\mathrm{L}$ and TRAIL pathways. Thus, we conjectured that Fox $\mathrm{O} 1$ could be involved in follicular atresia by the regulation of Fas L and TRAIL expression. Indeed, Fox O1 expression was significantly increased during follicular atresia. Furthermore, we investigated the phosphorylation and intracellular distribution of Fox $\mathrm{O} 1$ in granulosa cells. Fox O1 protein was detected in the nucleus of granulosa cells, but phosphorylated Fox O1 was localized to the cytoplasm. Fox O1, acting as a transcription factor, may contribute directly to the increased Fas L and TRAIL expression during follicular atresia. Analysis of the 5'-regulatory sequence of the porcine TRAIL gene revealed a Fox O1 binding site (Furuyama et al., 2000), with the sequence 'TTGTTTAC', at -77 bp. This further confirms our hypothesis. However, final confirmation of the direct regulation of TRAIL expression by Fox $\mathrm{O} 1$ requires further direct experimental evidence, such as by CHIP analysis.

\section{CONCLUSIONS}

Follicles 3-5 mm in diameter undergo atresia mainly through the TRAIL and Fas L pathways in pigs. The patterns of Fox $\mathrm{O} 1$ gene expression and intracellular localization observed in this study indicate the involvement of this transcription factor in the regulation of follicular atresia.

\section{ACKNOWLEDGMENTS}

Research supported by the Key Project of Chinese National Programs for Fundamental Research and Development (“973” Program \#2007CB947403).

\section{REFERENCES}

Alikhani M, Alikhani Z and Graves DT (2005). FOXO1 functions as a master switch that regulates gene expression necessary for tumor necrosis factor-induced fibroblast apoptosis. J. Biol. Chem. 280: 12096-12102.

Alonso-Pozos I, Rosales-Torres AM, Avalos-Rodriguez A, Vergara-Onofre M, et al. (2003). Mechanism of granulosa cell death during follicular atresia depends on follicular size. Theriogenology 60: 1071-1081.

Arden KC and Biggs WH, III (2002). Regulation of the FoxO family of transcription factors by phosphatidylinositol-3 kinase-activated signaling. Arch. Biochem. Biophys. 403: 292-298.

Biggs WH, III, Meisenhelder J, Hunter T, Cavenee WK, et al. (1999). Protein kinase B/Akt-mediated phosphorylation promotes nuclear exclusion of the winged helix transcription factor FKHR1. Proc. Natl. Acad. Sci. U. S. A. 96: 7421-7426.

Birkenkamp KU and Coffer PJ (2003). Regulation of cell survival and proliferation by the FOXO (Forkhead box, class O) subfamily of Forkhead transcription factors. Biochem. Soc. Trans. 31: 292-297.

Brunet A, Bonni A, Zigmond MJ, Lin MZ, et al. (1999). Akt promotes cell survival by phosphorylating and inhibiting a Forkhead transcription factor. Cell 96: 857-868.

Carter ME and Brunet A (2007). FOXO transcription factors. Curr. Biol. 17: R113-R114.

Cheng Y, Inoue N, Matsuda-Minehata F, Goto Y, et al. (2005). Changes in expression and localization of connexin 43 mRNA and protein in porcine ovary granulosa cells during follicular atresia. J. Reprod. Dev. 51: 627-637. 
Cheng Y, Maeda A, Goto Y, Matsuda F, et al. (2008). Changes in expression and localization of X-linked inhibitor of apoptosis protein (XIAP) in follicular granulosa cells during atresia in porcine ovaries. J. Reprod. Dev. 54: 454-459.

Furuyama T, Nakazawa T, Nakano I and Mori N (2000). Identification of the differential distribution patterns of mRNAs and consensus binding sequences for mouse DAF-16 homologues. Biochem. J. 349: 629-634.

Gilley J, Coffer PJ and Ham J (2003). FOXO transcription factors directly activate bim gene expression and promote apoptosis in sympathetic neurons. J. Cell Biol. 162: 613-622.

Grotowski W, Lecybyl R, Warenik-Szymankiewicz A and Trzeciak WH (1997). The role of apoptosis of granulosa cells in follicular atresia. Ginekol. Pol. 68: 317-326.

Hussein MR (2005). Apoptosis in the ovary: molecular mechanisms. Hum. Reprod. Update 11: 162-177.

Kaipia A and Hsueh AJ (1997). Regulation of ovarian follicle atresia. Annu. Rev. Physiol. 59: 349-363.

Kimura Y, Manabe N, Nishihara S, Matsushita H, et al. (1999). Up-regulation of the alpha2,6-sialyltransferase messenger ribonucleic acid increases glycoconjugates containing alpha2, 6-linked sialic acid residues in granulosa cells during follicular atresia of porcine ovaries. Biol. Reprod. 60: 1475-1482.

Maeda A, Inoue N, Matsuda-Minehata F, Goto Y, et al. (2007). The role of interleukin-6 in the regulation of granulosa cell apoptosis during follicular atresia in pig ovaries. J. Reprod. Dev. 53: 481-490.

Manabe N, Goto Y, Matsuda-Minehata F, Inoue N, et al. (2004). Regulation mechanism of selective atresia in porcine follicles: regulation of granulosa cell apoptosis during atresia. J. Reprod. Dev. 50: 493-514.

Manabe N, Matsuda-Minehata F, Goto Y, Maeda A, et al. (2008). Role of cell death ligand and receptor system on regulation of follicular atresia in pig ovaries. Reprod. Domest. Anim. 43 (Suppl 2): 268-272.

Matsuda-Minehata F, Goto Y, Inoue N and Manabe N (2005). Changes in expression of anti-apoptotic protein, cFLIP, in granulosa cells during follicular atresia in porcine ovaries. Mol. Reprod. Dev. 72: 145-151.

Matsuda-Minehata F, Inoue N, Goto Y and Manabe N (2006). The regulation of ovarian granulosa cell death by pro- and anti-apoptotic molecules. J. Reprod. Dev. 52: 695-705.

Matsuda F, Inoue N, Goto Y, Maeda A, et al. (2008). cFLIP regulates death receptor-mediated apoptosis in an ovarian granulosa cell line by inhibiting procaspase-8 cleavage. J. Reprod. Dev. 54: 314-320.

McLoughlin TJ, Smith SM, DeLong AD, Wang H, et al. (2009). FoxO1 induces apoptosis in skeletal myotubes in a DNAbinding-dependent manner. Am. J. Physiol. Cell Physiol. 297: C548-C555.

Modur V, Nagarajan R, Evers BM and Milbrandt J (2002). FOXO proteins regulate tumor necrosis factor-related apoptosis inducing ligand expression. Implications for PTEN mutation in prostate cancer. J. Biol. Chem. 277: 47928-47937.

Neufeld TP (2003). Shrinkage control: regulation of insulin-mediated growth by FOXO transcription factors. J. Biol. 2: 18.

Rolaki A, Drakakis P, Millingos S, Loutradis D, et al. (2005). Novel trends in follicular development, atresia and corpus luteum regression: a role for apoptosis. Reprod. Biomed. Online 11: 93-103.

Schmidt M, Fernandez de MS, van der Horst A, Klompmaker R, et al. (2002). Cell cycle inhibition by FoxO forkhead transcription factors involves downregulation of cyclin D. Mol. Cell Biol. 22: 7842-7852.

Sugimoto M, Kagawa N, Morita M, Kume S, et al. (2010). Changes in the expression of decoy receptor 3 in granulosa cells during follicular atresia in porcine ovaries. J. Reprod. Dev. 56: 467-474.

Takagi K, Yamada T, Miki Y, Umegaki T, et al. (2007). Histological observation of the development of follicles and follicular atresia in immature rat ovaries. Acta Med. Okayama 61: 283-298.

Wada S, Manabe N, Nakayama M, Inou N, et al. (2002). TRAIL-decoy receptor 1 plays inhibitory role in apoptosis of granulosa cells from pig ovarian follicles. J. Vet. Med. Sci. 64: 435-439. 